\title{
Deadly coronavirus found in bats
}

Discovery hints at virus's source, but how it spreads to humans remains unknown.

\section{Beth Mole}

23 August 2013

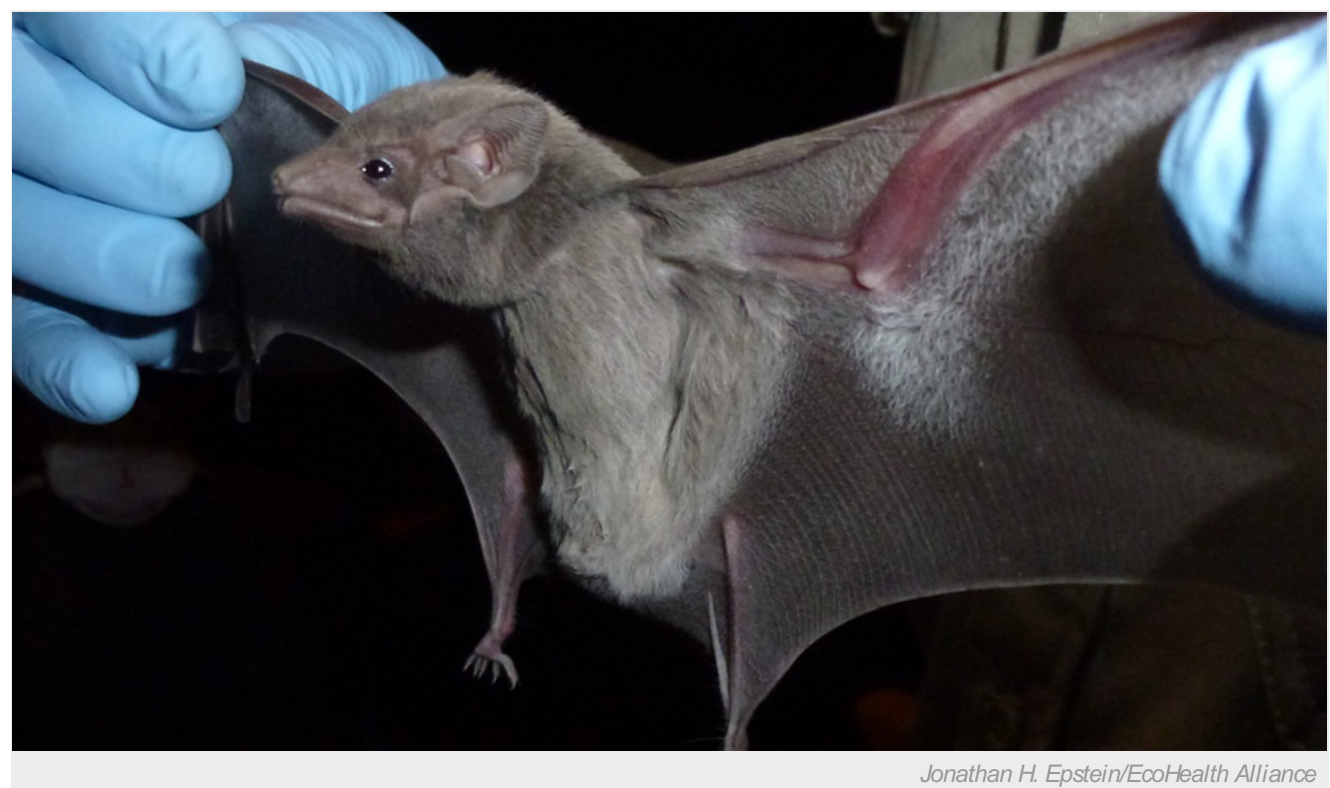

Scientists believe that the Egyptian tomb bat is a resenvir for a new coronavirus.

Bats have been pinpointed as a source of the coronavirus that has infected 94 people, killing 47 of them, since it emerged in the Middle East in April last year.

An international team of researchers has found a tiny genetic fragment that seems to be from the virus in a faecal sample from an Egyptian tomb bat ${ }^{1}$. The scientists surveyed 96 bats in Saudi Arabia in October and April, after the first cases of Middle East respiratory syndrome coronavirus (MERS-CoV) were reported there.

"Although it's a short fragment, because it's 100\% identical, it indicates this is the same virus," says epidemiologist lan Lipkin of Columbia University in New York city who led the study. His team reported the result on 21 August in the journal Emerging Infectious Diseases.

Because bats carry many types of coronavirus, it was widely thought that they were the ultimate source of MERS-CoV, which causes severe pneumonia in humans. But researchers have struggled to gather information that could help them to understand how the virus spreads, including which animals transmit the infection.

\section{Identity crisis}

Lipkin believes that he has got solid proof that bats are a reservoir for the virus. But other researchers are not convinced that the fragment his team has identified confirms the presence of MERS-CoV. Chantal Reusken, an infectious-disease researcher at the National Institute for Public Health and the Environment in Bilthoven, the Netherlands, points to weaknesses in the data linking the bat virus to the MERS-CoV that infects humans.

Reusken notes that the study authors could sequence only a 190-nucleotide-long segment of the 30,000-nucleotide coronavirus genome. Studies have suggested that sequences of at least 800 nucleotides are necessary to accurately determine how closely viruses are related ${ }^{2}$.

"It can absolutely not be ruled out that it is a sequence derived not from MERS-CoV but from another, closely related MERS-CoV like virus," Reusken says. 
Patrick Chiu Yat Woo, a bat-coronavirus expert at the University of Hong Kong, agrees. "The finding is, of course, important, but it has to be reproduced by others, and it has to be found in other bats." Woo says that when a new coronavirus is found, the whole genome should be sequenced if possible. Small differences in the genomes of related viruses can hint at the types of animal that a virus infects.

So far, camels are the only other animal implicated in the spread of MERS-CoV, on the basis of the results of blood antibody tests ${ }^{3}$. But because few people encounter bats or camels, researchers speculate that other animals spread the virus to humans.

Despite the gaps in these latest findings, Stanley Perlman, a coronavirus researcher at the University of lowa in lowa City, says the research is important because it confirms that bats carry MERS-CoV or a related virus. "It's certainly closely related," he says, "but you can't say how closely related."

Nature | doi:10.1038/nature.2013.13597

\section{References}

1. Memish, Z. A. et al. Emerg. Infect. Dis. http://dx.doi.org/10.3201/eid1911.131172 (2013).

2. Drexler, J. F. et al. J. Virol. 84, 11336-11349 (2010).

3. Reusken, C. B. et al. Lancet Infect. Dis. http://dx.doi.org/10.1016/S1473-3099(13)70164-6 (2013). 